\title{
Metabolic Clearance and Plasma Appearance Rates of Catecholamines in Preterm and Term Fetal Sheep
}

\author{
JAMES F. PADBURY, JOHN K. LUDLOW, JAMES A. HUMME, AND YOUTARO AGATA \\ Perinatal Research Laboratory, Department of Pediatrics, Harbor-UCLA Medical Center, UCLA School of \\ Medicine, Torrance, California 90509
}

\begin{abstract}
Plasma catecholamines increase markedly during labor and delivery. Moreover we have noted greater increases at birth in preterm than term lambs. It was unclear whether these differences were due to differences in secretion or clearance. We therefore designed experiments to compare the metabolic clearance rates (MCR) and plasma appearance rates of norepinephrine (NE) and epinephrine (E) in chronically catheterized term (143 \pm 1 days) and preterm (131 \pm 1 days) fetal sheep. Two different techniques, radioisotope tracer techniques and infusion of cold hormones for estimation of clearance rates, were compared systematically in the same group of animals. The results demonstrate that MCR of NE in term fetuses $\left(178 \pm 28 \mathrm{ml} \cdot \mathrm{kg}^{-1} \mathrm{~min}^{-1}\right)$ is similar to preterm fetuses $\left(205 \pm 22 \mathrm{ml} \cdot \mathrm{kg}^{-1} \mathrm{~min}^{-1}\right)$ as is MCR for E $(193 \pm 28$ versus $170 \pm 33 \mathrm{ml} \cdot \mathrm{kg}^{-1} \mathrm{~min}^{-1}$, respectively). Estimates of MCR from cold hormone infusion were highly dependent on infusion rate with estimtes as much as $150 \%$ above that determined by isotope tracer infusions. Plasma appearance rates for both $\mathrm{NE}$ and $\mathrm{E}$ in term and preterm animals were similar. There were no detectable physiologic alterations during the tracer isotope infusions whereas infusions of cold hormone were associated with marked alterations in heart rate and blood pressure. These results suggest: 1) there are no differences in MCR or plasma appearance rates of $\mathrm{NE}$ or $\mathrm{E}$ between 130 days gestational age and term fetal sheep; 2 ) cold hormone infusions overestimate MCR and plasma appearance rates of both NE and $E$ when compared to radioisotope tracer infusions; 3 ) differences in catecholamine concentrations at birth between term and preterm animals appear to be due to differences in secretion rather than clearance. (Pediatr Res 20: 992-995, 1986)
\end{abstract}

\section{Abbreviations}

MCR, metabolic clearance rate

PAR, plasma appearance rate

NE, norepinephrine

E, epinephrine

${ }^{3} \mathrm{H}-\mathrm{NE}$, tritiated norepinephrine

${ }^{3} \mathrm{H}-\mathrm{E}$, tritiated epinephrine

DPM, disintegrations per minute

Received March 6, 1986; accepted May 29, 1986.

Reprint requests James F. Padbury, Harbor-UCLA Medical Center, 1000 West Carson Street, Torrance, CA 90509.

Supported by grants from the National Institutes of Health HD-18014 and a Basil O'Connor starter Research Grant from the National Foundation March of Dimes.
Marked increases in plasma catecholamine concentrations in umbilical cord plasma and blood samples drawn in the first minutes and hours after birth have been described in newborn animals and humans (1-3). Moreover, we have noted greater increases in circulating catecholamines in both preterm sheep and human infants than in their term counterparts $(4,5)$. Increased urinary catecholamine and catecholamine metabolite excretion in preterm human infants compared with full term neonates suggests relatively increased catecholamine secretion and accounts for the higher blood levels in the premature infant (6). Whether the difference in plasma catecholamine levels at birth between term and preterm sheep is due to differences in catecholamine secretion or catecholamine clearance is not known.

The purpose of this study was to compare the metabolic clearance and plasma appearance rates of catecholamines in preterm and full term fetal sheep. Previous investigations have suggested that there are marked differences in estimated clearance rates, compared using radioisotope tracer techniques or cold hormone infusions (7). Thus, we compared the estimated clearance rates using both techniques in the same group of animals. The results suggest that metabolic clearance rates of catecholamines, which are similar in these preterm and term sheep, do not account for the greater elevations in plasma catecholamines noted in preterm animals and humans.

\section{MATERIALS AND METHODS}

Animals and surgery. Date-mated, Western, mixed-breed ewes with singleton pregnancies were used for all studies. Fetal catheterizations were performed at $125 \pm 1$ or $135 \pm 1$ days gestation. Animals were acclimated to the laboratory environment prior to surgery; food and water were withheld for $24 \mathrm{~h}$ prior to surgery. Animals were premedicated with ketamine (750 $\mathrm{mg}$ ) and atropine (1.2 $\mathrm{mg}$ ) followed by a continuous intravenous infusion of ketamine $(5 \mathrm{mg} / \mathrm{min})$. The maternal abdomen was shaved, prepped, and draped and the uterus exposed through a midline abdominal incision. The fetal hindlimb was identified, delivered through a small hysterotomy incision, and the hindlimb artery and vein were catheterized to the level of the midabdomen with polyethylene catheters (ID $1.02 \mathrm{~mm}$ ). The hysterotomy incision was repaired following insertion of an amniotic fluid catheter. The maternal femoral vein was catheterized and all catheters were tunneled, secured, and stored in a pouch on the maternal flank. Methicillin $(100 \mathrm{mg} / \mathrm{kg}$ ) was given to the fetus and methicillin and chloramphenicol (1 g each) to the ewes on the day of surgery and daily thereafter for 5 days.

Catecholamine infusions. After a minimum of 5 days postoperative recovery, fetuses were randomly assigned on alternate days to receive either ${ }^{3} \mathrm{H}-\mathrm{NE},{ }^{3} \mathrm{H}-\mathrm{E}$, cold NE, or cold E. In order to compare clearance and production rates at or near the gesta- 
tional ages originally studied at birth (4), infusions were begun at $130 \pm 1(n=6)$ days gestation or $141 \pm 1(n=7)$ days gestation. ${ }^{3} \mathrm{H}-\mathrm{NE}(21-23 \mathrm{Ci} / \mathrm{mmol})$ and ${ }^{3} \mathrm{H}-\mathrm{E}(75-78 \mathrm{Ci} / \mathrm{mmol})$ were obtained from New England Nuclear Corporation and infused with modifications of the technique described by Esler et al. (7). The fetal arterial catheter was attached to a Statham $\mathrm{P} 23 \mathrm{DB}$ pressure transducer which was connected to a Sensormedics R-611 Rectilinear polygraph. Blood pressure was monitored continuously. Heart rate was monitored by a $9857 \mathrm{~B}$ cardiotachometer which was triggered by the arterial pulse. Approximately 0.2 to $0.3 \mu \mathrm{Ci} \cdot \mathrm{kg}^{-1} \cdot \mathrm{min}^{-1}$ was infused intravenously at $0.5 \mathrm{ml} \mathrm{min} \mathrm{m}^{-1}$. Preliminary studies demonstrated that steady state plasma radioactivity and specific activity of ${ }^{3} \mathrm{H}-\mathrm{NE}$, and ${ }^{3} \mathrm{H}$-E were achieved within $15 \mathrm{~min}$ of infusion and sustained for at least 60 minutes. Samples were therefore obtained at 10 and $0 \mathrm{~min}$ prior to the infusion and then again at 15,30, and $45 \mathrm{~min}$ during the radioisotope infusion.

For cold hormone infusions 1-NE bitartrate and 1-E bitartrate were obtained from Sigma Chemical Company. On the morning of infusion, preweighed catecholamine was dissolved in sterile normal saline and diluted for continuous intravenous infusion at $0.04,0.2,0.75,1.5$, and $3.0 \mu \mathrm{g}$ base $\cdot \mathrm{kg}^{-1} \cdot \mathrm{min}^{-1}$ through the venous catheter. Preliminary studies demonstrated that there was no degradation of catecholamine in the infusate during the course of the infusion and that steady-state catecholamine concentrations were observed within $15 \mathrm{~min}$ at all infusion rates. Catecholamine infusions were continued at each concentration for a 40-min period followed by the next higher concentration. Blood for catecholamines and other analyses was obtained twice during the baseline period and then again at 20 and $40 \mathrm{~min}$ into each infusion and replaced with heparinized maternal blood. There were no significant changes in plasma catecholamines in animals similarly infused with normal saline.

Analytical techniques. Blood taken at each sampling point was transferred immediately to chilled test tubes containing in final concentration $4 \mathrm{mM}$ EGTA and $3 \mathrm{mM}$ reduced glutathione. Arterial blood was taken for all samples. Plasma was separated immediately by centrifugation at $2500 \mathrm{rpm}$ at $4^{\circ} \mathrm{C}$, removed, and stored at $-70^{\circ} \mathrm{C}$ for catecholamine assay, usually within 1 or $2 \mathrm{wk}$. Arterial blood gases and $\mathrm{pH}$ were determined on a Radiometer blood gas analyzer calibrated at $-39^{\circ} \mathrm{C}$. Plasma catecholamines were measured directly on unextracted plasma by radioenzymatic assay as described previously (8). The assay is sensitive to $1-2 \mathrm{pg}$ of $\mathrm{NE}$ and $\mathrm{E}$.

For analysis of ${ }^{3} \mathrm{H}-\mathrm{NE}$ and ${ }^{3} \mathrm{H}-\mathrm{E}$ in plasma minor modifications of the methods described by Esler et al. (7) were used. To a test tube containing $50 \mathrm{mg}$ alumina we added $1 \mathrm{ml}$ freshly thawed plasma and $1 \mathrm{ml} 0.5 \mathrm{M}$ Tris $\mathrm{pH} 8.6$ containing $2 \%$ EDTA. The tubes were vortexed slowly for $2 \mathrm{~min}$ and then centrifuged at $2500 \mathrm{rpm}$ for $2 \mathrm{~min}$. The supernatant was removed and discarded and the alumina washed and sedimented three times with $2 \mathrm{ml}$ distilled water. Tritiated catecholamines were eluted from the alumina with $0.6 \mathrm{ml} 0.1 \mathrm{~N}$ perchloric acid. Following vortexing and centrifugation, $0.4 \mathrm{ml}$ of the perchloric acid was removed and added to $10 \mathrm{ml}$ Aquasol II (New England Nuclear) and counted in a liquid scintillation counter. All samples were processed in identical fashion under similar conditions of counting efficiency which was $32 \%$. The remainder of the perchloric extract was removed and stored at $-70^{\circ} \mathrm{C}$ for catecholamine assay.

Data analysis. When cold NE or E is infused into the circulation and stable plateau concentrations are achieved, metabolic clearance rate can be calculated from the following formula:

$$
\operatorname{MCR}\left(\mathrm{ml} \cdot \mathrm{kg}^{-1} \cdot \mathrm{min}^{-1}\right)=\frac{\begin{array}{c}
\text { infusion rate }\left(\mathrm{g} \cdot \mathrm{min}^{-1}\right) \\
\div \text { body wt }(\mathrm{kg})
\end{array}}{\begin{array}{l}
\text { steady state plasma }[\operatorname{conc}(\mu \mathrm{g} / \mathrm{ml}) \\
- \text { baseline plasma } \operatorname{conc}(\mu \mathrm{g} / \mathrm{ml})]
\end{array}}
$$

Using labeled ${ }^{3} \mathrm{H}-\mathrm{NE}$ and ${ }^{3} \mathrm{H}-\mathrm{E}$, the following formula was used to estimate clearance rate:

$$
\begin{array}{r}
\mathrm{MCR}\left(\mathrm{ml} \cdot \mathrm{kg}^{-1} \cdot \mathrm{min}^{-1}\right) \\
=\frac{\mathrm{H}-\mathrm{CAT} \text { infusion rate }\left(\mathrm{CPM} \cdot \mathrm{min}^{-1}\right)}{\div \text { body wt }(\mathrm{kg})} \\
\begin{array}{r}
\text { steady state plasma }{ }^{3} \mathrm{H}-\mathrm{CAT}\left(\mathrm{CPM} \cdot \mathrm{ml}^{-1}\right) \\
- \text { baseline }{ }^{3} \mathrm{H}-\mathrm{CAT}\left(\mathrm{CPM} \cdot \mathrm{ml}^{-1}\right)
\end{array}
\end{array}
$$

Plasma appearance rate was calculated using the following formula:

PAR $\left(\mathrm{pg} \cdot \mathrm{kg}^{-1} \cdot \mathrm{min}^{-1}\right)$

$=\operatorname{MCR}\left(\mathrm{ml} \cdot \mathrm{kg}^{-1} \cdot \mathrm{min}^{-1}\right) \times$ baseline plasma conc $\left(\mathrm{pg} \cdot \mathrm{ml}^{-1}\right)$

Statistical analysis. Production and clearance rates of NE or $\mathrm{E}$ in preterm and term animals were compared by unpaired $t$ test. Clearance rates of $\mathrm{NE}$ and $\mathrm{E}$ during cold hormone infusions at each concentration were compared by analysis of variance followed by Student-Newman-Keuls testing for group differences (9). A level of $p<0.05$ was considered significant.

\section{RESULTS}

Data showing plasma ${ }^{3} \mathrm{H}-\mathrm{NE}$ radioactivity during infusion of $131 \pm 1$ days gestation animals are shown in Figure 1 . Steady state levels of plasma ${ }^{3} \mathrm{H}-\mathrm{NE}$ were achieved by $15 \mathrm{~min}$ and maintained for up to $1 \mathrm{hr}$. Similar results were obtained for ${ }^{3} \mathrm{H}$ E infused into $131 \pm 1$ animals and ${ }^{3} \mathrm{H}-\mathrm{NE}$ and ${ }^{3} \mathrm{H}-\mathrm{E}$ infused into $143 \pm 1$ days gestation animals. There were no differences when plasma ${ }^{3} \mathrm{H}-\mathrm{NE}$ or ${ }^{3} \mathrm{H}-\mathrm{E}$ at each sample time were compared by analysis of variance (9). There was no change in plasma NE or E concentration which were measured with each sample for plasma radioactivity or in heart rate or blood pressure during the course of these infusions. The catecholamine values reported postinfusion were drawn with the final samples for plasma radioactivity. These data are shown in Table 1. Calculated metabolic clearance rates and plasma appearance rates also are shown in Table 1. There were no significant differences in MCR or PAR for either NE or E between term and preterm and animals.

Baseline plasma catecholamine levels and mean plasma catecholamine concentrations during the cold hormone infusions at the $0.04,0.2,0.75,1.5$, and $3.0 \mu \mathrm{g} \cdot \mathrm{kg}^{-1} \cdot \mathrm{min}^{-1}$ infusion rates are shown in Figure 2. Plasma NE increased from $321 \pm 53 \mathrm{pg} / \mathrm{ml}$ at 141 days and $379 \pm 66 \mathrm{pg} / \mathrm{ml}$ at 130 days to over $14,000 \mathrm{pg} /$ $\mathrm{ml}$ during these infusions. Heart rate, blood pressure, and other metabolic and physiologic changes were increased markedly during the course of these infusions. Peak systolic pressure increased in term animals to over $100 \mathrm{~mm} \mathrm{Hg}$ and in preterm animals to over $90 \mathrm{~mm} \mathrm{Hg}$. Peak heart rate responses over 200

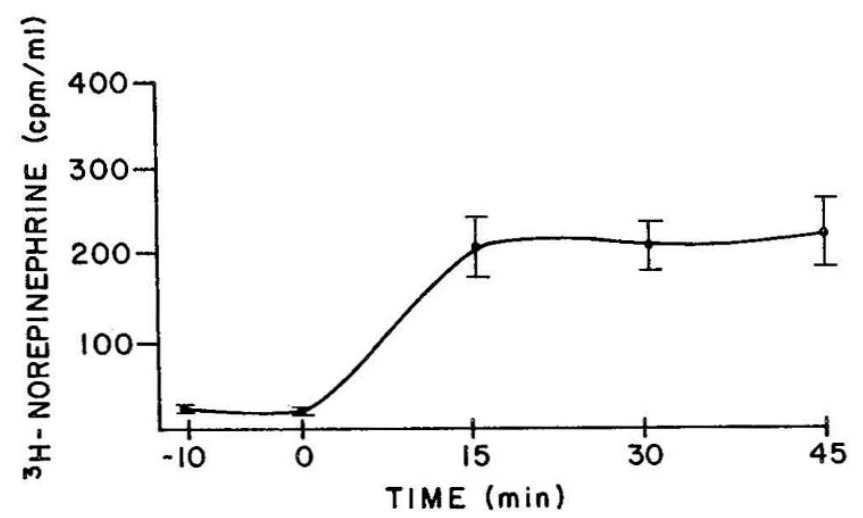

Fig. 1. Representative curve of plasma radioactivity during infusion of $0.2-0.3 \mu \mathrm{Ci} / \mathrm{kg} / \mathrm{min}$ tritiated epinephrine $(75.3-78.2 \mathrm{Ci} / \mathrm{mmol})$ into a $131 \pm 1$ days gestation fetal sheep. Baseline radioactivity represents background activity. Extraction techniques as outlined in "Methods." Mean \pm SEM . 
Table 1. Metabolic clearance and plasma appearance rate, catecholamine levels, and biophysical parameters during radioisotope infusions

\begin{tabular}{|c|c|c|c|c|c|c|c|c|c|}
\hline \multirow[b]{2}{*}{ Infusate } & \multirow{2}{*}{$\begin{array}{c}\text { Gestational age } \\
\text { (day) }\end{array}$} & \multicolumn{2}{|c|}{ Catecholamine $(\mathrm{pg} / \mathrm{ml})$} & \multicolumn{2}{|c|}{ Heart rate (BPM) } & \multicolumn{2}{|c|}{$\begin{array}{c}\text { Mean blood } \\
\text { pressure (mm } \\
\mathrm{Hg})\end{array}$} & \multirow{2}{*}{$\begin{array}{c}\text { MCR } \\
\left(\mathrm{ml} \mathrm{kg}^{-1} \min ^{-1}\right)\end{array}$} & \multirow{2}{*}{$\begin{array}{c}\text { PR } \\
\left(\mathrm{ng} \mathrm{kg}^{-1} \min ^{-1}\right)\end{array}$} \\
\hline & & Pre & Post & Pre & Post & Pre & Post & & \\
\hline${ }^{3} \mathrm{H}-\mathrm{NE}$ & $143 \pm 1(n=7)$ & $533 \pm 144$ & $581 \pm 81$ & $149 \pm 9$ & $149 \pm 7$ & $53 \pm 2$ & $53 \pm 2$ & $178 \pm 28$ & $120 \pm 39$ \\
\hline${ }^{3} \mathrm{H}-\mathrm{E}$ & $143 \pm 1(n=7)$ & $80 \pm 12$ & $53 \pm 2$ & $152 \pm 8$ & $147 \pm 7$ & $55 \pm 2$ & $56 \pm 2$ & $193 \pm 28$ & $12 \pm 3$ \\
\hline${ }^{3} \mathrm{H}-\mathrm{NE}$ & $131 \pm 1(n=6)$ & $621 \pm 80$ & $695 \pm 87$ & $180 \pm 7$ & $179 \pm 7$ & $46 \pm 2$ & $47 \pm 2$ & $205 \pm 22$ & $112 \pm 35$ \\
\hline${ }^{3} \mathrm{H}-\mathrm{E}$ & $131 \pm 1(n=6)$ & $41 \pm 11$ & $58 \pm 16$ & $170 \pm 6$ & $172 \pm 6$ & $46 \pm 3$ & $47 \pm 3$ & $170 \pm 33$ & $7.2 \pm 1$ \\
\hline
\end{tabular}
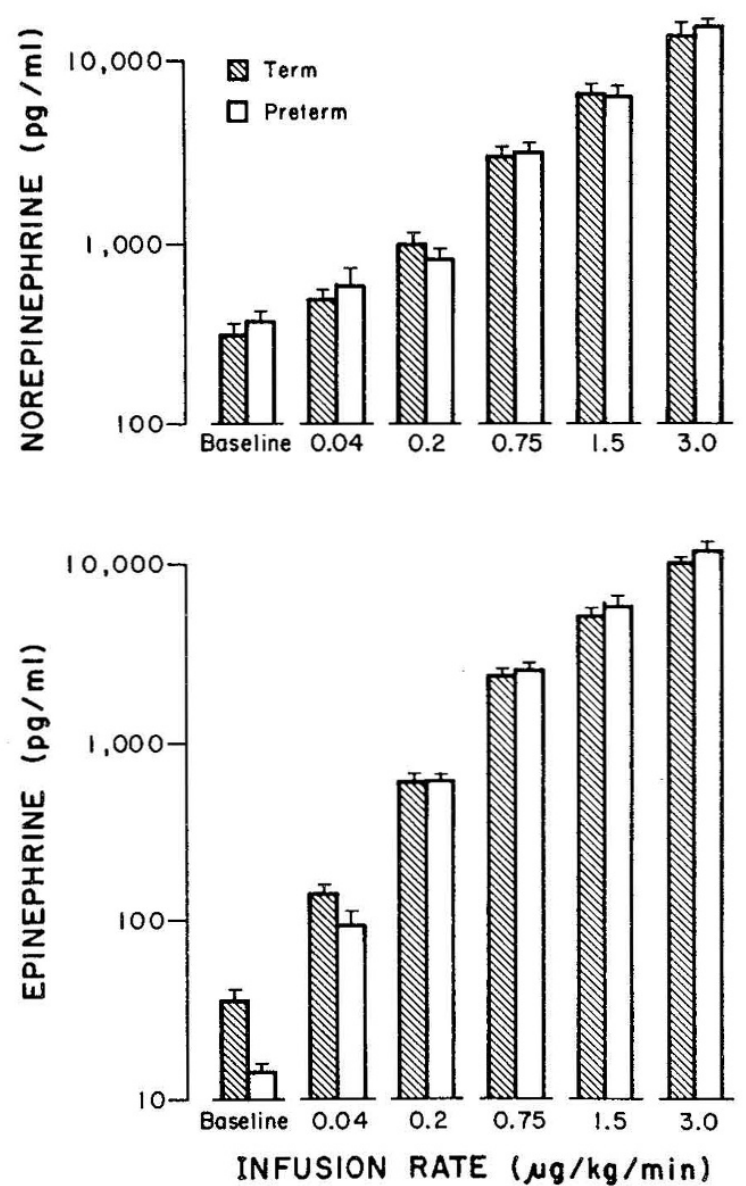

Fig. 2. Baseline plasma catecholamines and mean steady state plasma catecholamines in term (shaded bars) and preterm (open bars) fetal sheep during cold hormone infusions at rates indicated. Infusions and assay outlined in "Methods." Mean \pm SEM.

beats per minute were observed in both groups. The relationship of these changes to the plasma catecholamine levels is the subject of another report. These plasma catecholamine values achieved during cold hormone infusions were used to calculate apparent MCR as described. The NE and E MCR data for 141 and 130 days gestation are shown in Figure 3. For comparison, the MCRs from the isotope infusions also are shown. Apparent MCR was dependent on infusion rate. For NE at 141 days gestation MCR at $0.04 \mu \mathrm{g} \cdot \mathrm{kg}^{-1} \cdot \mathrm{min}^{-1}$ which was $250 \pm 55 \mathrm{ml} \cdot \mathrm{kg}^{-1} \cdot \mathrm{min}^{-1}$ rose to $335 \pm 45 \mathrm{ml} \cdot \mathrm{kg}^{-1} \cdot \mathrm{min}^{-1}$ at the $0.2 \mu \mathrm{g} \cdot \mathrm{kg}^{-1} \cdot \mathrm{min}^{-1}$ infusion rate and decreased to $244 \pm 45 \mathrm{ml} \cdot \mathrm{kg}^{-1} \cdot \mathrm{min}^{-1}$ at the highest infusion rate. At 131 days gestation apparent MCR for NE showed similar infusion rate dependent variations with estimates of $303 \pm 54 \mathrm{ml} \cdot \mathrm{kg}^{-1} \cdot \mathrm{min}^{-1}$ at the $0.2 \mu \mathrm{g} \cdot \mathrm{kg}^{-1} \cdot \mathrm{min}^{-1}$ infusion rate and $209 \pm 30 \mathrm{ml} \cdot \mathrm{kg}^{-1} \cdot \mathrm{min}^{-1}$ at the highest infusion rate. The apparent MCR for E at both 141 and 130 days gestation showed similar variations with infusion rate and these results are shown in the bottom panel of Figure 2.
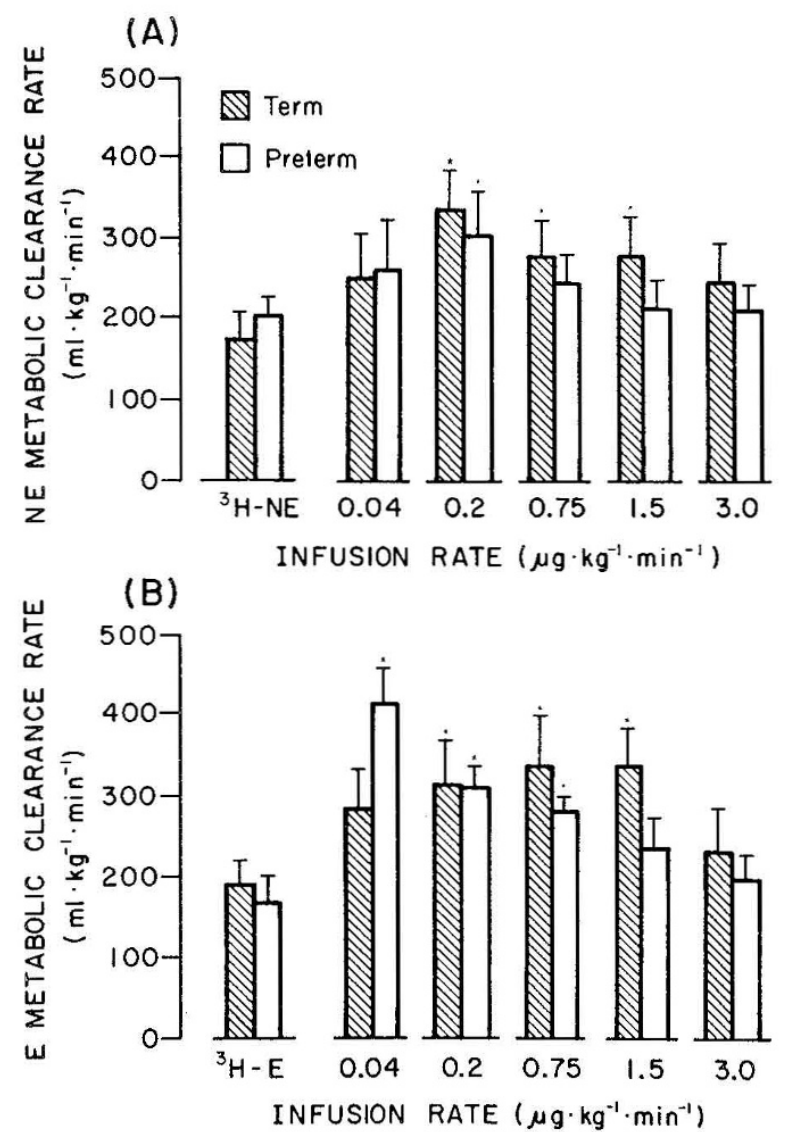

Fig. 3. Metabolic clearance rate of $\mathrm{NE}(A)$ and $\mathrm{E}(B)$ in term (shaded bars) and preterm (open bars) fetal sheep. Clearance values during radioisotope tracer infusions are compared with clearances during cold hormone infusions at rates indicated. Extraction techniques, assay, and data analysis as described in "Methods." Mean \pm SEM. Asterisk denotes significant difference tracer versus cold, $p<0.05$.

While not all the estimates of MCR from the cold hormone infusions were statistically greater than the estimates derived from the isotopic tracer infusions, cold hormone infusion yielded higher estimates at all infusion rates. This was true for both NE and $\mathrm{E}$ in both the term and preterm fetal sheep.

\section{DISCUSSION}

This study was undertaken to determine whether significant gestational age-related changes in catecholamine MCR could account for the marked variation in plasma catecholamines seen at birth in term and preterm sheep. Using infusion of tracer amounts of isotopically labeled $\mathrm{NE}$ and $\mathrm{E}$ we have shown that there are no significant differences in MCR between term (143 \pm 1 days) and preterm (131 \pm 1 days) chronically catheterized fetal sheep. There are only limited data available on catecholamine production and clearance rates in fetal sheep. Jones and Robinson (10) reported on clearance estimates using a single 
bolus-injection disappearance technique. However, because of the extremely short half-life of circulating plasma catecholamines and the need to obtain multiple, accurately timed samples over a short period of time, such a technique may introduce considerable error. Palmer et al. (11) used the constant infusion of cold hormone to steady state catecholamine levels to estimate E MCR in chronically catheterized fetuses. However, substantial physiologic alterations occurred, as a result of the $\mathrm{E}$ infusion to blood levels over $2000 \mathrm{pg} / \mathrm{ml}$. Their reported E MCR in near term animals, 258 to $264 \mathrm{ml} \cdot \mathrm{kg}^{-1} \cdot \mathrm{min}^{-1}$, is greater than the $170 \mathrm{ml}$. $\mathrm{kg}^{-1} \cdot \mathrm{min}^{-1}$ estimate derived using tracer infusions in the present study and comparable to the values we observed using cold hormone infusions.

The tracer isotope infusion technique is dependent on several now well-accepted assumptions. First, the label must be isotopically pure. This was guaranteed by the manufacturer at $>99 \%$ and confirmed in our laboratory by thin-layer chromatography. Second, steady state levels of radioactivity and specific activity are achieved during the infusion and there are no resultant physiological changes. These criteria were also fulfilled in this study. Finally the labeled hormone must mix homogeneously and completely with endogenously released hormone without significant uptake and release of the labeled hormone. This assumption is difficult to verify experimentally but experience with this technique suggests its validity (7). The extraction methods for separation of unmetabolized, labeled hormone from circulating, radioactive metabolites have been well characterized (7).

The catecholamine clearance values here represent steady-state estimates of the plasma appearance rate and disappearance rate or clearance. For both NE and E there are in fact multicompartmental, complex phenomena underlying these measurements ( 7 , 12). Plasma NE represents neurotransmitter released from postganglionic sympathetic neurons which has escaped neuronal reuptake and/or nonneuronal uptake and degradation as well as $\mathrm{NE}$ released from the adrenal medulla. Plasma $\mathrm{E}$ is derived exclusively from adrenal medullary secretion. Because steadystate kinetics provide the only reliable estimates of the appearance metabolic clearance and plasma appearance rates these studies were conducted in chronically catheterized animals rather than newborns. Nonetheless the results suggest that the differences in catecholamines at birth in term and preterm lambs are unlikely to be due to differences in secretion rather than clearance.

The apparent MCR during the infusion of unlabeled NE and $E$ was dependent on hormone infusion rate. Cold hormone infusions yielded higher estimates than tracer techniques at all infusion rates. The apparent MCR appeared to rise with increasing infusion rate and then to fall as exceedingly supraphysiologic levels of plasma catecholamines were achieved. These observations are consistent with saturation of an adrenergically mediated clearance mechanism. In fact previous studies suggest that plasma catecholamines are at least partially cleared by the $\beta \mathrm{ad}-$ renergically mediated mechanism $(12,13)$. In patients undergoing NE or E infusions at doses comparable to those used in this study, simultaneous treatment with $\beta$ blockers markedly increased the plasma concentrations of $\mathrm{NE}$ and $\mathrm{E}$ achieved during the course of the infusions (14). In that earlier report the authors did not report MCR estimates; however, other authors have noted infusion rate dependent effects on estimates of catechol- amine MCR $(12,13,15)$. The present study is the first to systematically compare MCR estimates from radioisotope infusions with multiple-dose cold hormone infusions in the same group of experimental subjects or animals. Other authors have suggested that cold catecholamine infusions, by inducing their own clearance, may lead to overestimates of MCR and PAR as was demonstrated in this study $(7,12,14,15)$.

In summary, our results demonstrate that MCR for NE and $\mathrm{E}$ in term and preterm chronically catheterized fetal sheep are similar. Further, MCR estimates from infusion of cold NE or E result in significant overestimations of clearance and production rate. The probable mechanism is both induction of beta adrenergically mediated clearance and physiologic alterations in blood flow and/or blood flow distribution. Additional studies of hormone kinetics in fetal animals should be conducted using tracer isotope methods rather than infusion of supraphysiologic doses of unlabeled hormone. Our results suggest that the increased plasma catecholamines observed at birth in preterm compared to term sheep are not due to differences in clearance but rather due to differences in secretion.

Acknowledgments. The authors thank Sharon Schuler and Prescilla Barrette for their help during the preparation of this manuscript.

\section{REFERENCES}

1. Lagercrantz H, Bistoletti P 1973 Catecholamine release in the newborn infant at birth. Pediatr Res 11:889-893

2. Padbury JF, Roberman B, Oddie TH, Hobel CJ, Fisher DA 1982 Fetal catecholamine release in response to labor and delivery. Obstet Gynecol 60:607-611

3. Padbury JF, Diakomanolis ES, Hobel CJ, Perelman A, Fisher DA 1981 Neonatal adaptation: sympatho-adrenal response to umbilical cord cutting. Pediatr Res 15:1483-1487

4. Padbury JF, Polk DH, Newnham JP, Lam RW 1985 Neonatal adaptation: greater sympathoadrenal response in preterm than full-term fetal sheep at birth. Am J Physiol 248(Endocrinol Metab 11):E443-E449

5. Newnham JP, Marshall CL, Padbury JF, Lam RW, Hobel CJ, Fisher DA 1984 Fetal catecholamine release with preterm delivery. Am J Obstet Gynecol 149:888-893

6. Dalmaz Y, Peyrin L, Dutruge J, Sann L 1980 Neonatal pattern of adrenergic metabolites in urine of small for gestational age and preterm infants. J Neural Transmission 49:151-165

7. Esler M, Jackman G, Bobik A, Kelleher D, Jennings G, Leonard P, Skews H, Korner P 1979 Determination of norepinephrine apparent release rate and clearance in humans. Life Sci 25:1461-1470

8. Peuler JD, Johnson GA 1977 Simultaneous single isotope radioenzymatic assay of plasma norepinephrine, epinephrine and dopamine. Life Sci 21:625636

9. Sokal R, Rohlf F 1969 Biometry. Freeman, San Francisco, CA

10. Jones CT, Robinson RO 1975 Plasma catecholemines in foetal and adult sheep. J Physiol 248:15-33

11. Palmer SM, Oakes GK, Lam RW, Hobel CJ, Fisher DA 1984 Catecholamine physiology in ovine fetus II. Metabolic clearance rate of epinephrine. Am J Physiol 246 (Endocrinol Metab 9):E350-E355

12. Clutter WE, Bier DM, Shah SD, Cryer PE 1980 Epinephrine plasma metabolic clearance rates and physiologic thresholds for metabolic and hemodynamic actions in man. $\mathbf{J}$ Clin Invest 66:94-101

13. Silverberg AB, Shah SD, Haymond MW, Cryer PE 1979 Norepinephrine: hormone and neurotransmitter in man. Am J Physiol 234:E252-E256

14. Hjemdahl P, Akerstedt T, Pollare T, Gillberg M 1983 Influence of $\beta$-adrenoceptor blockade by metoprolol and propranolol on plasma concentrations and effects of noradrenaline and adrenaline during i.v. infusion. Acta Physiol Scand 515:45-53

15. Wilkie FL, Halter JB, Prinz PN, Benedetti C, Eisdorfer C, Atwood B, Yamasaki D 1985 Age-related changes in venous catecholamines basally and during epinephrine infusion in man. J Gerontol 40:133-140 